\title{
Growth, XRD, Mechanical, Optical and SHG Studies of L-Lysine L-Tartaric Acid Crystals
}

\author{
C. Anbulakshmi ${ }^{1 *}$, P. Selvarajan ${ }^{2}$ and S. Selvaraj ${ }^{3}$ \\ ${ }^{1}$ Research Scholar, ${ }^{2}$ Associate Professor of Physics, ${ }^{3} \mathrm{HOD}$ and Associate Professor of Physics \\ ${ }^{1 \& 3}$ Department of Physics and Research Centre, The MDT Hindu College, Tirunelveli, Tamil Nadu, India \\ ${ }^{2}$ Aditanar College of Arts and Science, Tiruchendur, Tamil Nadu, India \\ (Affiliated to Manonmaniam Sundaranar University, Abishekapatti, Tirunelveli, Tamilnadu, India) \\ *Corresponding Author \\ E-Mail: sharmichandrasekaran@gmail.com
}

\begin{abstract}
Single crystals of L-lysine L-tartaric acid (LLLT) were grown by solution method using double distilled water as the solvent. The grown crystals LLLT were subjected to characterization studies like XRD studies, mechanical studies, optical studies and SHG studies. From XRD studies, it is ascertained that LLLT crystal crystallizes in monoclinic structure. The grown crystal has high transmittance in the visible region and it has high optical band gap. The mechanical parameters like hardness, work hardening coefficient, yield strength, stiffness constant, brittleness index, corrected hardness and resistance pressure of LLLT crystal have been evaluated by using Vickers microhardness method. The relative SHG efficiency of LLLT crystal has been determined by Kurtz-Perry powder technique.
\end{abstract}

Keywords: Single Crystal, Solution Growth, NLO, XRD, Hardness, Transmittance, Band Gap, Stiffness Constant, Yield Strength, SHG

\section{INTRODUCTION}

Nonlinear optical (NLO) crystals are the technologically important materials and they are gaining keen attention due to their enormous applications in emerging optoelectronics, fibre optic communication, optical computing, photonics and laser technology. Organic nonlinear optical (NLO) crystals have attracted much attention due to their high nonlinearity, low cost and flexibility of molecular design. Most of the organic NLO crystals are constructed by weak Vander walls and hydrogen bonds with conjugated $\pi$-electrons [1-3]. In this work, concentration is given on an organic NLO crystal viz., L-lysine L-tartaric acid crystal. Lysine is a $\alpha$-amino acid that is used in the biosynthesis of proteins. It contains an $\alpha$-amino group, an $\alpha$-carboxylic acid group and a side chain containing lysyl $\left(\left(\mathrm{CH}_{2}\right)_{4} \mathrm{NH}_{2}\right)$. Like almost all other amino acids, the $\alpha$-carbon is chiral and lysine may refer to either enantiomer or a racemic mixture of both [4, 5]. Here in this work, the biologically active enantiomer L-lysine has been considered for the crystal growth. Crystallographic data for L-lysine complexes exist in the literature. Carboxylic acids complexed with L-lysine have been studied by including formic, acetic, succinic, glycolic, oxalic, and maleic acids. The crystal structures of complexes of glutaric acid with D, L- and L-lysine were reported [6-10]. L-tartaric acid is an organic material and the salts of tartaric acid were intensively studied by means of structural, spectroscopic, optical and dielectric studies [11-15]. Some tartrates exhibit structural phase transitions and in many cases vibrational spectroscopy was effectively used to study the tartrates [16-20]. Based on the literature survey on L-lysine and tartaric acid, the work considered here is to prepare an organic complex like L-lysine Ltartaric acid (LLLT) by solution method. The aim of the research work is to grow and to study the single crystals of LLLT and the obtained results from the various studies of LLLT crystals are reported in this paper.

\section{EXPERIMENTAL}

\section{A. Synthesis and Solubility}

Analar Reagent (AR) grade chemicals of L-lysine and Ltartaric acid in the molar ratio of 1:1 were used for synthesis of L-lysine L-tartaric acid (LLLT) salt. The calculated amounts of reactants were dissolved in double distilled water and stirred well using a hot plate magnetic stirrer for about 3 hours. The solution was heated at $50{ }^{\circ} \mathrm{C}$ till the synthesized salt of LLLT was obtained. Solubility study was carried out by gravimetric method using a constant temperature bath (CTB). Initially, the temperature was maintained at $30{ }^{\circ} \mathrm{C}$ and the synthesized salt of LLLT was added step by step to $50 \mathrm{ml}$ of water in an air-tight container kept on the hot-plate magnetic stirrer and stirring was continued until the solution was saturated. By gravimetric method, the amount of solute present in the solution was found and from this value, the solubility was determined. In the similar manner, the solubility was found in the temperature range $30-50^{\circ} \mathrm{C}$. The variation of solubility with temperature for LLLT sample is presented in the fig.1. The result indicates that the solubility of LLLT sample in water increases with increase of temperature and hence this sample has positive temperature coefficient of solubility. In the solubility diagram, there are three regions or zones and they are (i) undersaturated region is below the solubility curve, (ii) supersaturated region is above the solubility curve and (iii) saturated region is along the solubility line. Usually, metastable zone or region is observed slightly above the solubility curve. Using the solubility data, saturated and supersaturated solution could be prepared at a 
particular temperature for crystal growth and crystal nucleation experiments [21].

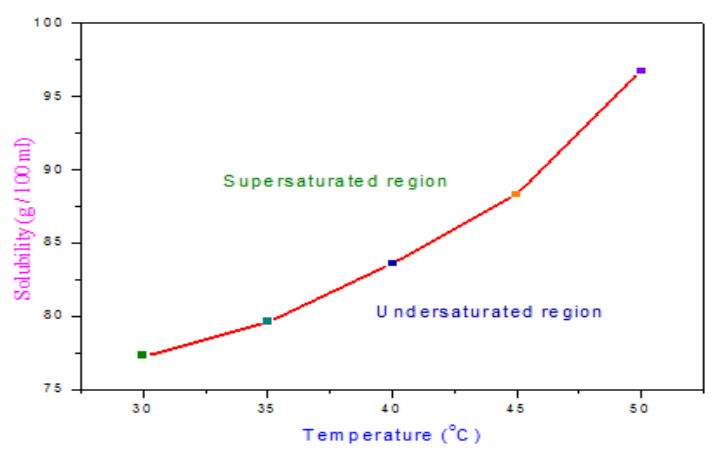

Fig. 1 Solubility curve for LLLT sample

\section{B. Crystal Growth}

Growth of single crystal of LLLT was carried out by solution method with slow evaporation technique. Using the solubility data, the saturated aqueous solution was prepared and stirred continuously about two hours to ensure homogeneous concentration throughout the volume of the solution. Then the solution was filtered by high quality Whatman filter papers to remove insoluble colloidal particles and the filtrate was kept in a controlled evaporation condition using a constant temperature bath (CTB). The seed crystals were obtained by spontaneous nucleation. To grow big-sized single crystals, some good quality seed crystals were immersed in the solution. The crystals were harvested after a growth period of 30 days and the photograph of the grown crystal of LLLT is displayed in the Fig. 2.

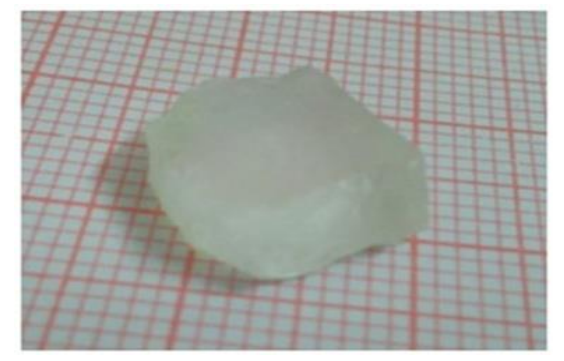

Fig. 2 A harvested crystal of LLLT

\section{XRD Studies}

The structural characterization for the grown LLLT crystal was carried out by single crystal XRD studies using on ENRAF NONIUS CAD4 diffractometer with Mo $\mathrm{K}_{\alpha}$ radiation $(\lambda=0.71073 \AA)$ and the obtained data are given in the table I. The data clearly indicates that the sample crystal crystallizes in monoclinic structure. The number of molecules per unit cell $(Z)$ is observed to be 2 for the sample and the space group is $\mathrm{P} 2_{1}$ and this space group is a non-centrosymmetric space group. Hence, this crystal can be a second harmonic generator and also it can produce third harmonic generation. The data of XRD obtained in this work for LLLT crystal are observed to be almost the same as reported in the literature [22].
TABLE I SingLe CRYSTAL XRd DATA Of LlLt CRYSTAL

\begin{tabular}{|l|c|c|c|c|}
\hline Sample & $\mathrm{a}(\AA)$ & $\mathrm{b}(\AA)$ & $\mathrm{c}(\AA)$ & $\mathrm{V}\left(\AA^{3}\right)$ \\
\hline $\begin{array}{l}\text { LLLT } \\
\text { crystal }\end{array}$ & $5.114(5)$ & $17.502(2)$ & $7.494(3)$ & $664.7(4)$ \\
\hline \multicolumn{4}{|c|}{$\begin{array}{c}\text { Space group }=\mathrm{P} 2_{1} \\
\text { Crystal system }=\text { Monoclinic; } \mathrm{Z}=2\end{array}$} \\
\multicolumn{4}{|c|}{ Angular lattice parameters $\alpha=90^{\circ}, \beta=98.05(4)^{\circ}, \gamma=90^{\circ}$}
\end{tabular}

\section{Microhardness and Other Mechanical Parameters}

Measurement of micro hardness is used for understanding the mechanical strength of the crystalline materials. The micro hardness's of the grown LLLT crystal were determined using Vickers hardness tester at room temperature. A well-polished crystal was used in this method. The loads used to find the microhardness are $25 \mathrm{~g}$, $50 \mathrm{~g}, 75 \mathrm{~g}, 100 \mathrm{~g}$ and $125 \mathrm{~g}$. Using a diamond indenter, the average value of at least two impressions was recorded for each load (P) and the average of diagonal indentation length (d) of the impression mark after unloading was measured using a calibrated micrometer attached to the eyepiece of the microscope. The plot of $\mathrm{d}$ versus $\mathrm{P}$ for the sample is shown in the fig.3. It is observed that the average indentation length (d) increases with increase of applied load and microhardness was determined using the values of d. The microhardness number $\left(\mathrm{H}_{\mathrm{v}}\right)$ can be calculated using the formula $\mathrm{H}_{\mathrm{v}}=1.8544 \mathrm{P} / \mathrm{d}^{2}$ where $\mathrm{P}$ is the load applied in gram and $\mathrm{d}$ is the diagonal length of the indentation in millimeter. The plot is drawn at different applied loads and it is shown in the fig. 4. The results indicate that the hardness of LLLT crystal increases with increase of the applied load up to $100 \mathrm{~g}$ and then it decreases. The increasing part corresponds to the reverse indentation size effect and the decreasing part is due to normal indentation size effect. Since small damage has been formed on the surface of the crystal when the applied load is more than $100 \mathrm{~g}$ and hence the hardness decreases beyond $100 \mathrm{~g}$. From the results, it is seen that LLLT crystal has both reverse indentation and normal indentation size effects. Since crack is formed when the load of $100 \mathrm{~g}$ is applied on the surface of the crystal, the fracture mechanism in the indentation process is explained here. The resistance to fracture is called as the toughness of the crystal and the fracture toughness $\left(\mathrm{F}_{\mathrm{t}}\right)$ can be determined using the relation $\mathrm{F}_{\mathrm{t}}=\mathrm{P} /\left(\beta l^{3 / 2}\right)$ where $P$ is the applied load and $\beta$ is a constant equal to 7 for Vickers diamond indenter and $l$ is the crack length measured from the centre of indentation to crack tip [23]. The calculated value of fracture toughness at $100 \mathrm{~g}$ is $0.1023 \mathrm{~g}$ $\mu \mathrm{m}^{-3 / 2}$. For the applied load 125 gram also, fracture toughness was determined and it is found to be $0.1874 \mathrm{~g}$ $\mu \mathrm{m}^{-3 / 2}$. Hence fracture toughness increases as the applied load increases for LLLT crystal. The brittleness index is related with the fracture induced in sample without any appreciable deformation and this value can be calculated using the relation $\beta_{\mathrm{r}}=\mathrm{H}_{\mathrm{v}} / \mathrm{F}_{\mathrm{t}}$ and the calculated values of brittleness index of LLLT crystal are $0.834 \mu^{-1 / 2}$ and $0.435 \mu^{-1 / 2}$ at $100 \mathrm{~g}$ and $125 \mathrm{~g}$ respectively. 


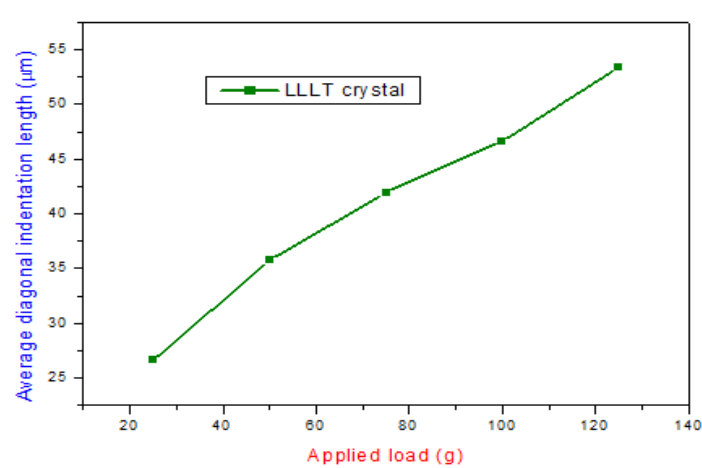

Fig. 3 Plot of average indentation length (d) with applied load (P) for LLLT crystal

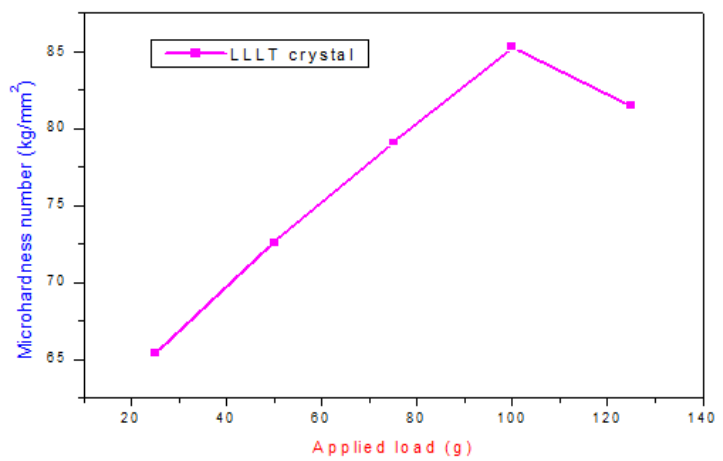

Fig. 4 Variation of micro hardness with applied load for LLLT crystal

Using the values of hardness, the work hardening coefficient of the sample was evaluated. Here the Meyer's equation $\mathrm{P}=\mathrm{ad}^{\mathrm{n}}$ was used. Here $\mathrm{P}$ is the load, $\mathrm{n}$ is the work hardening coefficient, $d$ is average indentation length and a is a constant. The plot of $\log (\mathrm{P})$ versus $\log (\mathrm{d})$ for LLLT crystal was drawn and it is shown in the fig.5. The slope of the plot is obtained to be 2.583 and this is equal to work hardening coefficient. According to Onitsch and Hanneman, the work hardening coefficient (n) should lie below 1.6 for hard materials and ' $n$ ' should lie above 1.6 for soft materials. Hence, the grown LLLT crystal is the category of soft materials.

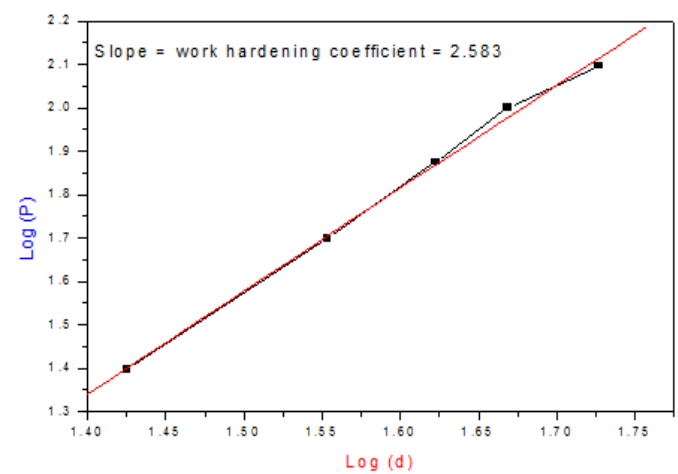

Fig.5 Plot of $\log (\mathrm{P})$ versus $\log (\mathrm{d})$ for LLLT crystal

Yield strength ( $\sigma y)$ of the grown LLLT crystal was determined using the following relation $\sigma_{\mathrm{y}}=\left(\mathrm{H}_{\mathrm{v}} / 3\right)[1-(\mathrm{n}-2)][12.5(\mathrm{n}-2) /(1-\mathrm{n}+2)] \mathrm{n}-2$

Another mechanical parameter viz., stiffness constant was calculated using the Wooster's empirical relation and it is given by $\mathrm{C}_{11}=\left(\mathrm{H}_{\mathrm{v}}\right)^{7 / 4}$ where $\mathrm{H}_{\mathrm{v}}$ is the Vickers microhardness number [24]. The calculated values of yield strength and stiffness constant of LLLT crystal are given in the table II. The obtained results indicate that both yield strength and stiffness constant increase upto $100 \mathrm{~g}$ and then these values decrease when the load applied is more than $100 \mathrm{~g}$.

TABLE II OBTAINED VALUES OF YIELD STRENGTH AND STIFFNESS CONSTANT OF LLLT CRYSTALS

\begin{tabular}{|c|c|c|}
\hline Applied load (g) & $\begin{array}{c}\text { Yield strength } \\
\mathbf{x ~ 1 0} \mathbf{( M P a})\end{array}$ & $\begin{array}{c}\text { Stiffness constant } \\
\text { (MPa) }\end{array}$ \\
\hline 25 & 488.425 & $2.58171 \mathrm{E}+15$ \\
\hline 50 & 542.196 & $3.09945 \mathrm{E}+15$ \\
\hline 75 & 590.740 & $3.60126 \mathrm{E}+15$ \\
\hline 100 & 637.043 & $4.10967 \mathrm{E}+15$ \\
\hline 125 & 608.664 & $3.79465 \mathrm{E}+15$ \\
\hline
\end{tabular}

Hays-Kendall's relation is given by $\mathrm{P}=\mathrm{W}+\mathrm{Ad}^{2}$ where $\mathrm{P}$ is the applied load, $\mathrm{d}$ is the average diagonal indentation length, $\mathrm{W}$ is the minimum load to initiate plastic deformation in gram $(\mathrm{g})$ or resistance pressure and $\mathrm{A}$ is the load-independent constant. The values of $\mathrm{W}$ and $\mathrm{A}$ are obtained from the plot drawn between $P$ versus $\mathrm{d}^{2}$ as shown in the fig.6. Load-independent constant is obtained to be A $=0.04813 \mathrm{~g} / \mu^{2}$. The resultant value of $\mathrm{W}$ becomes negative and hence the sample exhibits behavior of reverse indentation size effect. The corrected indentation size independent hardness $\left(\mathrm{H}_{0}\right)$ is determined using the relation $\mathrm{H}_{0}=1.8544 \mathrm{~A}$. The obtained values of $\mathrm{W}$ and $\mathrm{H}_{\mathrm{o}}$ for LLLT crystal are $-9.3329 \mathrm{~g}$ and $0.0893 \mathrm{~g} / \mu \mathrm{m}^{2}$ respectively.

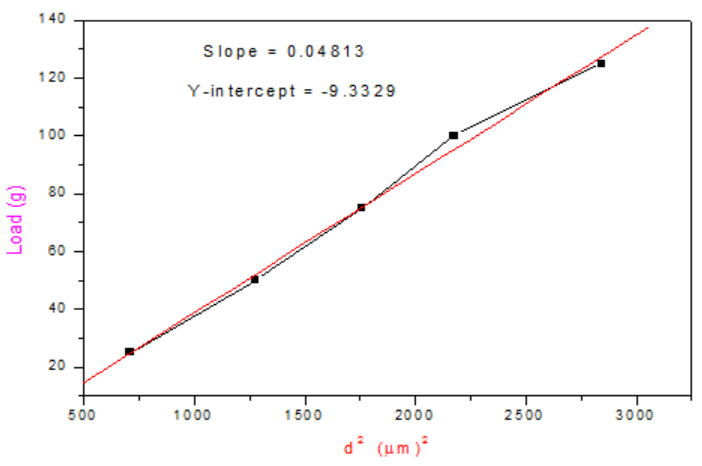

Fig.6 Plot of P versus $\mathrm{d}^{2}$ for LLLT crystal

To verify the values obtained from Hays-Kendall's approach (HK model), another model viz., the proportional specimen resistance (PSR) model is considered here. According to PSR model, the indentation load $(\mathrm{P})$ in terms of average diagonal indentation length (d) is given by $\mathrm{P}=\mathrm{ad}$ $+\mathrm{bd}^{2}$ where $\mathrm{a}$ is the load-dependent constant and $\mathrm{b}$ is a load-independent constant. The constant $\mathrm{b}$ can be obtained from the plot of $\mathrm{P} / \mathrm{d}$ against $\mathrm{d}$ as shown in fig.7. From the plot, the slope obtained is $0.0551 \mathrm{~g} / \mu^{2}$ and this value is equal to the value of $b$ which is equal to the resistance pressure. The corrected independent hardness $\left(\mathrm{H}_{\mathrm{o}}{ }^{\prime}\right)$ can be calculated using the relation $\mathrm{H}_{\mathrm{o}}{ }^{\prime}=1.8544 \mathrm{~b}$ and the obtained 
value is $0.0966 \mathrm{~g} / \mu \mathrm{m}^{2}$. The values of load independent constant and corrected independent hardness for LLLT crystal obtained from HK model and PSR model are given in the table 3 and the values obtained from both HK and PSR models are noticed to be almost the same.

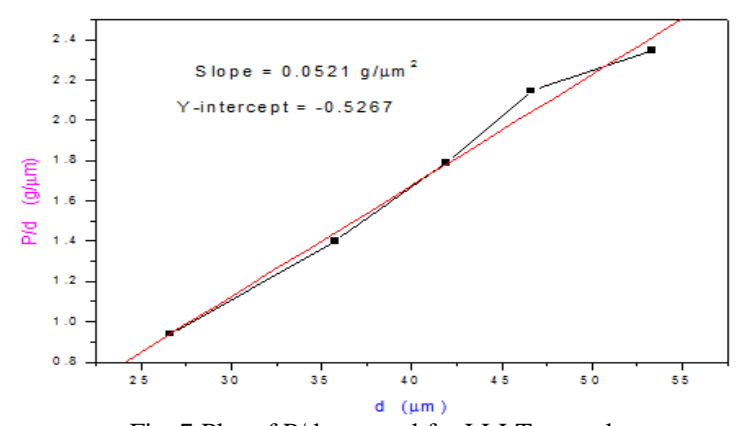

Fig. 7 Plot of P/d versus d for LLLT crystal

TABLE III VALUES OF LOAD INDEPENDENT CONSTANT AND CORRECTED INDEPENDENT HARDNESS FOR LLLT CR YSTAL

\begin{tabular}{|l|c|c|}
\hline \multicolumn{1}{|c|}{ Parameters } & HK model & PSR model \\
\hline $\begin{array}{l}\text { Load independent } \\
\text { constant }\end{array}$ & $0.04813 \mathrm{~g} / \mu \mathrm{m}^{2}$ & $0.0521 \mathrm{~g} / \mu \mathrm{m}^{2}$ \\
\hline $\begin{array}{l}\text { Corrected independent } \\
\text { Hardness }\end{array}$ & $0.0893 \mathrm{~g} / \mu \mathrm{m}^{2}$ & $0.0966 \mathrm{~g} / \mu^{2}$ \\
\hline
\end{tabular}

\section{E. Optical Characterization}

Optical characterization was carried out by recording the UV-visible-NIR transmittance/absorbance spectra of LLLT crystal in the wavelength range 190-1100 $\mathrm{nm}$. The recorded transmittance and absorbance spectra of the sample are shown in the fig. 8 and 9. From the transmittance spectrum, it is observed that the sample has high transmittance in the entire visible-NIR region of the spectrum. The UV cut-off wavelength is noticed at $210 \mathrm{~nm}$ for LLLT crystal and this absorption of light in the sample is due to the fundamental absorption and this is due to electronic transitions associated with the sample. Using the equation $\mathrm{E}_{\mathrm{g}}=1242 / \lambda \quad(\mathrm{nm})$, the optical band gap value was calculated to be $5.914 \mathrm{eV}$ for LLLT crystal. The value of optical band of the sample was also obtained from Tauc's plot and this plot can be drawn using the relation

$$
\alpha h v=A \sqrt{\left(h v-E_{g}\right)}
$$

where $E_{\mathrm{g}}$ is the optical band gap energy of the crystal, $\alpha$ is the absorption coefficient, $h$ is the Planck's constant, $v$ is the frequency of the light and $\mathrm{A}$ is a constant [25]. The absorption coefficient $(\alpha)$ of the sample is determined using the following equation

$$
\alpha=(2.303 / \mathrm{d}) *\left[\log _{10}(1 / \mathrm{T})\right]
$$

where $\mathrm{T}$ is the transmittance and $\mathrm{d}$ is the thickness of the crystal. The variation of absorption coefficient with wavelength for LLLT crystal is presented in the fig.10. It is observed that the absorption coefficient is very high at 210 $\mathrm{nm}$ and this corresponds to the fundamental absorption of the sample. Using the values of absorption coefficient, Tauc's plot is drawn and it is shown in the fig.11. From the plot, the optical band gap of the grown LLLT crystal was obtained to be $5.92 \mathrm{eV}$. Reflectance spectrum of LLLT crystal is drawn and it is shown the fig. 12 and from the figure it observed that the value of reflectance is high at 210 $\mathrm{nm}$ and it is also found to be decreasing with increase of wavelength in the UV-visible region.

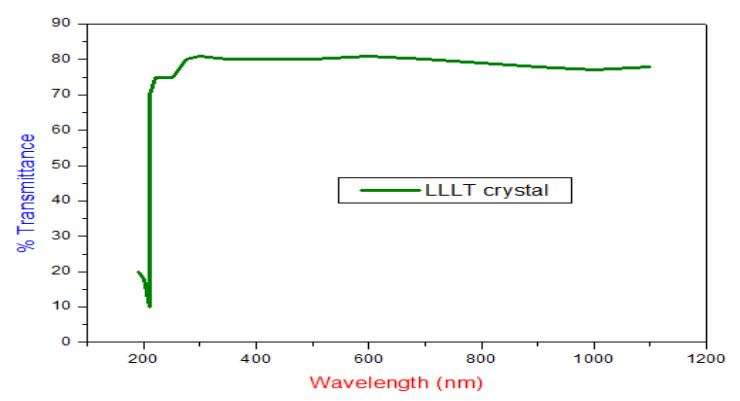

Fig. 8 Transmittance spectrum of LLLT crystal

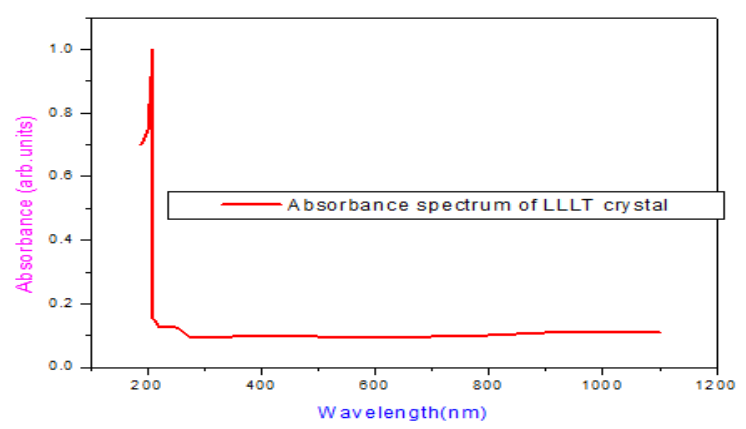

Fig. 9 Absorbance spectrum of LLLT crystal

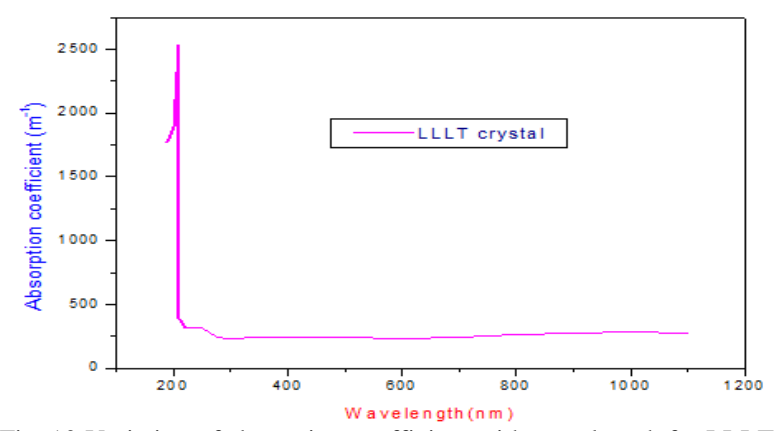

Fig. 10 Variation of absorption coefficient with wavelength for LLLT crystal

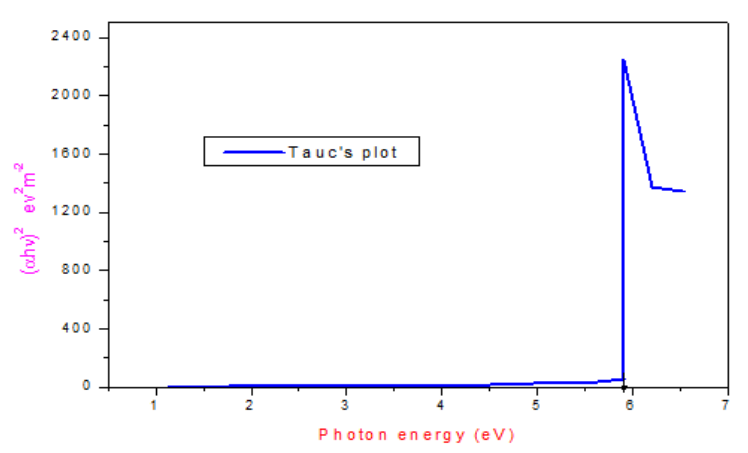

Fig. 11 Tauc's plot of LLLT crystal 


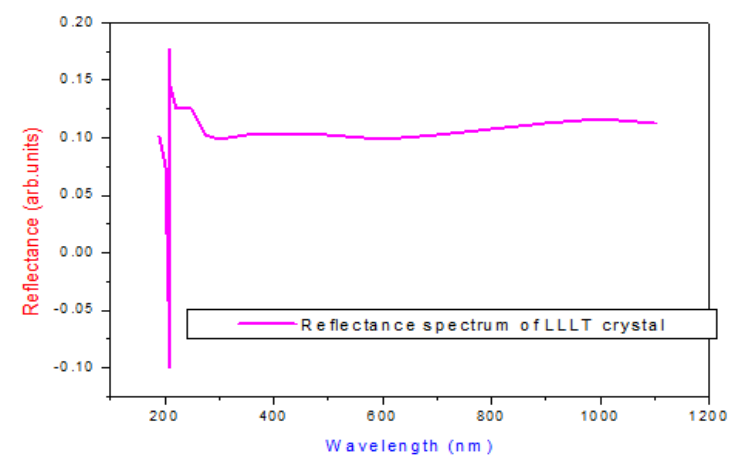

Fig. 12 Reflectance spectrum of LLLT crystal

\section{F. Second Order NLO Studies}

Second order NLO studies were carried out by using KurtzPerry powder technique [26] and this technique is a convenient method for the measurement of relative SHG efficiency of LLLT crystal. Here Q-switched Nd: YAG laser of wavelength of $1064 \mathrm{~nm}$ was directed onto a powdered sample and the emitted light is collected, filtered and detected with a photo multiplier tube. The sample is in the form of fine powder of known grain size and pressed between two glass plates. The ratio of the fundamental and second harmonic intensities determines the relative SHG efficiency of the sample. The SHG efficiency varies with the grain size of the powdered sample. To eliminate the experimental error, urea or KDP sample of the same size is tested in the same experimental set-up and the efficiency is evaluated as a ratio. Both the reference and test samples must have the uniform particle size of 125 to 250 microns. In this method, it is noticed that there is an emission of green radiation with a wavelength of $532 \mathrm{~nm}$ from the sample. The second harmonic generation signal of 11.22 $\mathrm{mJ} /$ pulse was observed for LLLT sample for an input energy of $0.70 \mathrm{~J} /$ pulse. But the standard KDP sample gave an SHG signal of $8.91 \mathrm{~mJ} /$ pulse for the same input energy. Hence, relative SHG efficiency of LLLT crystal is 1.26 times that of the KDP sample. The data obtained from SHG measurement for LLLT crystal are provided in the table IV.

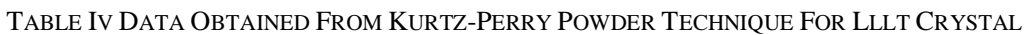

\begin{tabular}{|c|l|c|c|c|}
\hline S. No. & Sample name & $\begin{array}{c}\text { Output energy } \\
\text { (milli joule/pulse) }\end{array}$ & $\begin{array}{c}\text { Input energy } \\
\text { (joule/pulse) }\end{array}$ & Relative SHG efficiency \\
\hline 1 & LLLT crystal & 11.22 & 0.70 & 1.26 \\
\hline 2 & KDP (Reference) & 8.91 & 0.70 & 1 \\
\hline
\end{tabular}

\section{CONCLUSION}

The solution method with slow evaporation technique was adopted to grow the single crystals of LLLT. XRD studies reveal that LLLT crystal has monoclinic structure with space group $\mathrm{P} 2{ }_{1}$. The hardness, stiffness constant, yield strength of the grown crystal of LLLT are observed to be high. The optical band gap of LLLT crystal was found to be $5.92 \mathrm{eV}$ and UV cut-off wave length of the sample is observed at $210 \mathrm{~nm}$. The relative SHG efficiency of LLLT crystal is found to be 1.26 times that of the KDP sample. Since the grown crystal of L-lysine L-tartaric acid (LLLT) has the non-centrosymmetric structure, has high transparency, high optical band gap and high SHG efficiency, it could be used for fabrication of second order NLO devices.

\section{REFERENCES}

[1] J. Ledourx, J. Badan, J. Zyss, A. Migus, D. Hulin, J. Etchepare, G. Grillon and A. Antonetti, "Generation of high-peak-power tunable infrared femto second pulses in an organic crystal: application to time resolution of weak infrared signals", J. Opt. Soc. Am. Vol.4, pp. 987997, 1987.

[2] S. Boomadevi, H.P. Mittal, R. Dhansekaran, S. Boomadevi, H. P.Mittal and R. Dhansekaran, "Synthesis, Crystal Growth and Characterization of 3-Methyl 4-Nitropyridine 1-Oxide (POM) Single Crystals," J. Crystal Growth., Vol. 261, pp. 55-62, 2004.

[3] N.J. Long and Angew. "Organo-metallic compounds for nonlinear optics-The Search for Enlightenment", Chem. Int. Ed. Engl., Vol. 34, pp. 21-38, 1995.

[4] M. K. Marchewka, S. Debrus and H. Ratajczak, "Vibrational Spectra and Second Harmonic Generation in Molecular Complexes of L-
Lysine with L-Tartaric, D, L-Malic, Acetic, Arsenous, and Fumaric Acids", Crystal Growth Des, Vol.3, pp. 587-592, 2003.

[5] N. Srinivasan, B. Sridhar and R.K. Rajaram, "L-Lysine L-lysinium dichloride nitrate" Acta Crystallogr, Vol. 57, pp. 888-890, 2001

[6] S. Suresh, G. S. Prasad and M. Vijayan, "X-ray studies on crystalline complexes involving amino acids and peptides and crystal structure of two forms of L-histidine acetate and a comparative study of the amino acid complexes of acetic acid". Int. J. Pept. Protein Res. Vol. 43, pp. 139-145, 1994.

[7] S. Suresh, M. Vijayan and J. Biosci, "Variability in ionization state, stoichiometry and aggregation in histidine complexes with formic acid", Journal of Biosciences, Vol. 20, pp. 225-234, 1995.

[8] N.R. Chandra, M. M. Prabu, M. M. Venkataraman, S. Suresh, M. Vijayan, "Amino Acids, Peptides and Proteins", Acta Crystallogr., Vol. 54, pp. 257, 1998.

[9] J. Pratap, V. Ravishankar and R. Vijayan, "M. X-ray studies on crystalline complexes involving amino acids and peptides. Invariance and variability in amino acid aggregation in the complexes of Maleic acid with L-histidine and L-lysine", Acta Crystallogr, Vol. 56, pp. 690-696, 2000.

[10] N. Saraswathi, T, Manoj, and N.Vijayan, M, "X-ray studies on crystalline complexes involving amino acids and peptides. Novel aggregation patterns and effect of chirality in the complexes of DLand L-lysine with glutaric acid", Acta Crystallogr, Vol. 57, pp. 366$371,2001$.

[11] P.L. Polavarapu, C.S. Ewig, and T. Chandramouly, "Conformtions of tartaric acid and Its Esters”, J. Am. Chem. Soc. Vol.109, pp. 7382, 1987.

[12] M. Koralewski, and M. Szafranski, "1-lysine-1-tartaric acid: new molecular complex with nonlinear optical properties", Ferroelectrics, Vol. 80, pp. 917, 1988.

[13] M. Koralewski and Szafranski, "Optical activity, domain structure and deflection of light at domain walls in lithium ammonium tartrate monohydrate" Ferroelectrics, Vol. 97, pp. 233, 1989.

[14] M. Maeda, K. Honda, and I. Suzuki, "Dielectric, Elastic and Piezoelectric Properties of the Mixed Crystals System Na $\left[\mathrm{K}_{1-x}\left(\mathrm{NH}_{4}\right)\right.$ x]-Tartrate $(0.90<x<1.0)$ ", J. Phys. Soc. Jpn. Vol. 7 pp. 2642-2649, 1995. 
[15] K. Deguchi, and Y. Iwata, "Effects of Deuteration on DisplaciveType Ferroelectric Phase Transition of $\mathrm{LiTlC}_{4} \mathrm{H}_{4} \mathrm{O}_{6} \cdot \mathrm{H}_{2} \mathrm{O}$ ", J. Phys. Soc. Jpn. Vol. 69, pp. 135-138, 2000.

[16] B. Gerth, A. Sahling, G. Pompe, E. Hegenbarth, and B. Brezina, "Ferroelectric Properties of Solid Solutions of Triglycine Sulfate and Fluoberyllate Crystals", Phys. Stat. Sol. (A), Vol. 57, pp. K153, 1980.

[17] M.M. Abdelkader, Z.H. Eltanahy, M. Abutaleb, A. Abousehly, and A. Elsharkawy, "l-lysine-1-tartaric acid: New molecular complex with nonlinear optical properties. Structure, vibrational spectra and phase transitions", Philos. Mag. B., Vol. 72, pp. 91, 1995.

[18] Kanesaka, H. Kita, "Vibrational study on phase transition in ammonium Rochelle salt", J. Raman Spectrosc. Vol. 23, pp. 585, 1992.

[19] P. Kolandaivel, and S. Selvasekarapandian, "Laser Raman and FT-IR spectrum of ammonium hydrogen tartrate and potassium hydrogen tartrate crystals". Cryst. Res. Tech. Vol. 28, pp. 665, 1993.

[20] S. Kamba, B. Brezina, J. Petzelt, and G. Schaack, "Study of the phase transition in lithium ammonium tartrate monohydrate by means of infrared and Raman spectroscopy". Journal of Phys.: Condens Matter, Vol. 8, pp. 8669, 1996.
[21] D. Shanthi, P. Selvarajan, K.K. Hema Durga, and S. Lincy Mary Ponmani, "Nucleation kinetics, growth and studies of $\beta$-alanine single crystals" Spectrochimica Acta Part A, Vol. 110, pp. 1-6, 2013.

[22] S. Debrus, M.K. Marchewk, J. Baran, M. Drozd, R. Czopnik, A. Pietraszko, and H. Ratajczak, "L-lysine-L-tartaric acid: New molecular complex with nonlinear optical properties. Structure, vibrational spectra and phase transitions", J.Solid State Chemistry, Vol. 178, pp. 2880-2896, 2005.

[23] H. Ishikaa, and N. Skinkai, "Critical Load for Median crack initiation in vickers indentation of Glasses", J. Am. Ceram. Soc., Vol. 65, pp. 124-127, 1982.

[24] W.A. Wooster, "Physical properties and atomic arrangements in crystals", Rep. Prog. Phys., Vol. 16, pp. 62-82, 1953.

[25] J. Tauc., R. Grigorovici, and A. Vancu, "Optical properties and electronic structure of amorphous Germanium”, Physica status solid, Vol. 15, pp. 627-637, 1996.

[26] S.K. Kurtz, and T.T. Perry, "A Powder Technique for the evaluation of nonlinear optical Materials", J. Appl. Phys, Vol. 39, pp. 3798$3813,1968$. 